\title{
Corticosteroids as adjunctive treatment in Austrian's syndrome (pneumococcal endocarditis, meningitis, and pneumonia): report of two cases and review of the literature
}

\author{
D du Cheyron, A Lesage, $O$ Le Page, F Flais, R Leclercq, P Charbonneau
}

J Clin Pathol 2003;56:879-881

This report describes two cases of Osler's triad of pneumonia, meningitis, and endocarditis, as a result of Streptococcus pneumoniae infection, also called Austrian's syndrome. In the first patient, a 51 year old non-alcoholic man, the aortic valve was affected and needed to be replaced in an emergency operation. The mitral valve was affected in a 70 year old woman without underlying disease, who only benefited from medical treatment. Both patients received corticosteroids, either dexamethasone followed by low doses of hydrocortisone and fludrocortisone, or only hydrocortisone and fludrocortisone, at the onset of the illness, and their outcome was favourable. These case reports focus on the presentation, prognosis, and therapeutic options for this severe syndrome.

l: $\mathrm{n}$ the antibiotic era, Streptococcus pneumoniae endocarditis is responsible for less than 3\% of all cases of endocarditis in native valves. Nonetheless, the mortality rate remains high and the incidence of pneumococcal resistance to penicillin has increased worldwide during the past 10 years. ${ }^{1}$ An uncommon entity of $S$ pneumoniae endocarditis associated with meningitis and pneumonia was described by Osler in 1881; this disease is also called Austrian's syndrome, and is more prevalent in alcoholic patients. ${ }^{2-4}$ We report two rare cases of aortic and mitral endocarditis in acute Osler's triad in non-alcoholic patients, and emphasise the importance of: (1) an early diagnosis of endocarditis in cases of pneumococcal meningitis, and (2) providing adequate medical or combined medical-surgical treatment, including corticosteroids, without delay.

"The incidence of pneumococcal resistance to penicillin has increased worldwide during the past 10 years"

\section{CASE REPORT 1}

Table 1 shows the presenting characteristics of the two patients reported here.

A 51 year old man, with chronic underlying disease, including hypertension and peripheral arteriopathy, was admitted to our intensive care unit (ICU) with fever, polypnea, a Glasgow coma scale score of 8 , and meningeal signs. A lumbar puncture showed the following features in the cerebrospinal fluid (CSF): glucose concentration, $0 \mathrm{mmol} /$ litre with glycaemia in normal range; protein concentration, $4 \mathrm{~g} / \mathrm{litre}$; leucocyte count, 425/ $\mu \mathrm{l}$ (40\% neutrophils and $60 \%$ lymphocytes); and Gram positive cocci on Gram stain. Cardiac auscultation detected no abnormality, and haemodynamic status was conserved. A chest $x$ ray showed a basal right lobe infiltrate, associated with severe hypoxaemia. He was intubated, and treated intravenously with empirical chemotherapy comprising cefotaxime, amoxicillin, and vancomycin. Twenty four hours later, he suddenly presented a grade III atrioventricular (AV) block of 10 minutes duration with transient hypotension, and a major aortic murmur was detected. Transoesophageal echocardiography was performed, and showed a large sigmoid vegetation with massive aortic insufficiency; no perivalvular abscess was seen. Within eight hours of the grade III AV block, his haemodynamic status dramatically deteriorated, and he developed multiple organ failure syndrome, despite the use of vasopressors, associated with low doses of hydrocortisone and fludrocortisone. No otitis media, sinusitis, or embolic complication was disclosed with injected computed tomography (CT). A further episode of grade III AV block required rapid valve replacement. Valve substitution by prosthetic aortic valve was performed 36 hours after his admission, revealing a destroyed valve and a septal perforated abscess with interatrial communication. Blood, vegetation, bronchoalveolar, and CSF cultures were positive for $S$ pneumoniae. Cefotaxime and vancomycin were withdrawn when the amoxicillin minimum inhibitory concentration (MIC) was known $(<0.5 \mu \mathrm{g} / \mathrm{ml})$. Amoxicillin was given for the next four weeks, in combination with aminoglycosides for 15 days. The patient was discharged from the ICU a few weeks later, with moderate altered mental status.

\section{CASE REPORT 2}

A 70 year old woman with no underlying disease was intubated in the ICU for a Glasgow coma scale score of 7 , meningeal signs, and severe community acquired pneumonia. Cranial CT findings were within normal limits. The CSF biology was as follow: glucose concentration, $0 \mathrm{mmol} / \mathrm{litre}$; protein concentration, $6.5 \mathrm{~g} / \mathrm{litre}$; and leucocyte count, $125 / \mu \mathrm{l}$ (80\% neutrophils). Gram stain on CSF was positive. Initial treatment was cefotaxime and vancomycin, combined with dexamethasone. Twenty four hours after admission to the ICU she developed septic shock with renal failure. A new mitral murmur was detected on cardiac auscultation. Transoesophageal echocardiography identified a small mitral vegetation with moderate insufficiency. Dexamethasone was withdrawn and low doses of hydrocortisone and fludrocortisone were given for seven days. CSF, bronchoalveolar fluid, and blood cultures were positive for $S$ pneumoniae. The isolate was highly resistant to penicillin (MIC, $5 \mu \mathrm{g} / \mathrm{ml}$ ) and cefotaxime (MIC, $4 \mu \mathrm{g} / \mathrm{ml}$ ). Nonetheless, the patient was

Abbreviations: AV, atrioventricular; $\mathrm{CT}$, computed tomography; $\mathrm{CSF}$, cerebrospinal fluid; ICU, intensive care unit; MIC, minimum inhibitory concentration 
Table 1 Baseline characteristics of the two patients with pneumococcal Osler's triad

\begin{tabular}{|c|c|c|}
\hline Characteristic & Patient 1 & Patient 2 \\
\hline Age & 51 years & 70 years \\
\hline Sex & Male & Female \\
\hline Underlying disease & Hypertension, peripheral arteriopathy & - \\
\hline Primary localisation & Pneumonia and meningitis & Pneumonia and meningitis \\
\hline Endocarditis features & $\begin{array}{l}24 \text { hour delayed diagnosis, aortic } \\
\text { endocarditis, large vegetation; massive } \\
\text { aortic insufficiency, perivalvular abscess, } \\
\text { interatrial communication }\end{array}$ & $\begin{array}{l}28 \text { hour delayed diagnosis, mitral } \\
\text { endocarditis, small vegetation, } \\
\text { moderate mitral insufficiency }\end{array}$ \\
\hline $\begin{array}{l}\text { Empirical intravenous } \\
\text { antimicrobial chemotherapy }\end{array}$ & $\begin{array}{l}\text { Amoxicillin }(2 \mathrm{~g} / 4 \mathrm{~h}) \text {, cefotaxime } \\
(2 \mathrm{~g} / 4 \mathrm{~h}) \text {, vancomycin }(2 \mathrm{~g} / \text { day })\end{array}$ & $\begin{array}{l}\text { Cefotaxime }(2 \mathrm{~g} / 4 \mathrm{~h}) \text {, vancomycin } \\
(2 \mathrm{~g} / \text { day) }\end{array}$ \\
\hline Combined treatment & - & Dexamethasone (10 mg/6 h) \\
\hline $\begin{array}{l}\text { Isolation of Streptococcus } \\
\text { pneumoniae }\end{array}$ & $\begin{array}{l}\text { Blood, vegetation, CSF (culture), } \\
\text { bronchoalveolar fluid }\end{array}$ & $\begin{array}{l}\text { Blood, vegetation, CSF (Gram } \\
\text { stain+culture), bronchoalveolar fluid }\end{array}$ \\
\hline S pneumoniae MIC & $\begin{array}{l}\text { Penicillin sensitive, amoxicillin: } \\
<0.5 \mu \mathrm{g} / \mathrm{ml}\end{array}$ & $\begin{array}{l}\text { Penicillin resistant, amoxicillin: } \\
5 \mu \mathrm{g} / \mathrm{ml} \text {; cefotaxime: } 4 \mu \mathrm{g} / \mathrm{ml}\end{array}$ \\
\hline $\begin{array}{l}\text { Adapted antimicrobial } \\
\text { treatment }\end{array}$ & Amoxicillin, gentamicin & Rifampicin, vancomycin \\
\hline Evolution & $\begin{array}{l}\text { Septic and cardiogenic shocks } \\
\text { and III AV block, acute }\end{array}$ & Septic shock, subacute \\
\hline Organ failure & $\begin{array}{l}\text { Neurological, respiratory, } \\
\text { haemodynamic, renal, disseminated } \\
\text { intravascular coagulopathy }\end{array}$ & $\begin{array}{l}\text { Neurological, respiratory, } \\
\text { haemodynamic, renal }\end{array}$ \\
\hline $\begin{array}{l}\text { Vasopressor support } \\
(\mu \mathrm{g} / \mathrm{kg} / \mathrm{min})\end{array}$ & $\begin{array}{l}\text { Dobutamine }(15) \text {, noradrenaline } \\
\text { (1.2), isoprenaline }(10 \mu \mathrm{g} / \mathrm{min})\end{array}$ & $\begin{array}{l}\text { Dobutamine (5), noradrenaline } \\
(0.5)\end{array}$ \\
\hline Corticosteroids, 7 days & $\begin{array}{l}\text { Hydrocortisone ( } 200 \mathrm{mg} / \text { day }) \text {, } \\
\text { fludrocortisone }(50 \mu \mathrm{g} / \text { day })\end{array}$ & $\begin{array}{l}\text { Hydrocortisone ( } 200 \mathrm{mg} / \text { day }) \text {, } \\
\text { fludrocortisone ( } 50 \mu \mathrm{g} / \text { day })\end{array}$ \\
\hline Surgical treatment & Aortic valve substitution & - \\
\hline ICU length before discharge & 5 weeks & 3 weeks \\
\hline Mental status at ICU discharge & Moderate disability & Normal \\
\hline
\end{tabular}

treated successfully for six weeks with vancomycin and rifampicin.

\section{DISCUSSION}

Most invasive pneumococcal infections occur in debilitated middle aged men with predisposing factors, such as chronic alcoholism, altered immune state, dural fistula, and ear or sinus infection. ${ }^{4}$ Streptococcus pneumoniae remains the most frequent microbial agent of community acquired bacterial meningitis in adults, with high mortality (25\%) and morbidity rates despite adequate antibiotics, combined or not with corticosteroids. ${ }^{56}$

Staphylococcus aureus is the most prevalent pathogen responsible for native or prosthetic valve endocarditis in patients admitted to the ICU, and prognosis is poor. ${ }^{78}$ Only a small proportion of cases of community acquired endocarditis are caused by $S$ pneumionae, with the same predisposing factors as meningitis. ${ }^{4}$ In pneumococcal endocarditis, the native aortic valve is the most frequent localisation of the vegetation. ${ }^{3}$ Despite adequate antibiotics, the evolution is usually acute and very aggressive, with a high rate of local (perforated perivalvular abscesses) and systemic complications, requiring surgical treatment in most cases. ${ }^{4}{ }^{9} \mathrm{~A}$ subacute evolution is less frequent and often involves mitral endocarditis. ${ }^{10}$

The usual portal of entry for Osler's triad is the lung, followed by cardiac valve ${ }^{10}$ or meningeal ${ }^{11}$ localisations; the third site of the triad usually appears when high doses of appropriate antibiotics are delivered. In a recent retrospective study concerning 80 cases of pneumococcal meningitis in the ICU, only six patients developed endocarditis, which caused cardiogenic shock, then death in two patients. ${ }^{5}$ Similarly, in the largest described cohort of pneumococcal endocarditis (325 patients), only three patients presented with the triad. ${ }^{3}$ However, Aronin et al reported a $42 \%$ prevalence of Osler's triad in a review of pneumococcal endocarditis in the penicillin era, with a mortality rate greater than $50 \%{ }^{4}$
"Valve replacement must be performed as soon as possible to avoid the development of cardiogenic shock and consequent multiorgan failure syndrome when the aortic valve is involved"

It is essential to measure the MIC for penicillin because many strains of $S$ pneumoniae have developed a degree of penicillin resistance during the past few decades. In acute bacterial meningitis or endocarditis, expert recommendations propose empirical initial treatment with a combination of drugs such as cefotaxime and vancomycin, until penicillin or cefotaxime MICs are known, ${ }^{12}{ }^{13}$ then a combination of vancomycin and rifampicin should be considered if pneumococcal isolates show full resistance to cefotaxime (MIC, $>2 \mu \mathrm{g} / \mathrm{ml}$ ). ${ }^{12}$ By following these recommendations, nonsusceptibility to penicillin $\mathrm{G}$ does not seem to be associated with a worse outcome. ${ }^{511}$ Nevertheless, valve replacement must be performed as soon as possible to avoid the development of cardiogenic shock and consequent multiorgan failure syndrome when the aortic valve is involved, whereas medical treatment alone may be adequate in some cases of mitral endocarditis. ${ }^{4}{ }^{9}$

In addition to an adequate medical or combined medicalsurgical approach, corticosteroids may be beneficial in these severe patients. Indeed, early treatment with dexamethasone improves the outcome in adults with pneumococcal meningitis, ${ }^{6}$ despite a possible dexamethasone induced decrease in CSF vancomycin concentrations. The mechanism involved may be modulation of the immunological response to stress which results in a reduction in the inflammatory response. In addition, low doses of hydrocortisone and fludrocotisone restore haemodynamic stability in cases of disseminated pneumoccocal infections with septic shock. ${ }^{14}$ Thus, further studies are needed to clarify the precise dose and composition of any steroid supplement, and might result in improvements in the corticosteroid induced increase in cerebral perfusion and decrease in the inflammatory response to stress, which 


\section{Take home messages}

- Patients with pneumococcal Osler's triad are still seen relatively frequently in the intensive care unit, and the disease still has a poor outcome

- It is important that the appropriate medical or combined medical-surgical treatment is instituted promptly

- In addition to antibiotics, corticosteroids (dexamethasone, and low doses of hydrocortisone and fludrocortisone) have been successful in treating meningitis and septic shock and could help decrease the mortality and morbidity rates associated with this severe disease

could reduce morbidity and mortality rates in invasive pneumococcal infections.

In summary, pneumococcal Osler's triad is seen not infrequently in the ICU, and is still associated with a poor outcome. The appropriate medical or combined medicalsurgical treatment needs to be discussed promptly. Moreover, because dexamethasone has been used successfully to treat meningitis and low doses of hydrocortisone and fludrocortisone to treat septic shock, the addition of corticosteroids may decrease the mortality and morbidity rates in this severe disease.

\section{Authors' affiliations}

D du Cheyron, A Lesage, P Charbonneau, Department of Medical Intensive Care, University Hospital of Caen, 14000 Caen, France O Le Page, Department of Thoracic and Cardiovascular Surgery, University Hospital of Caen

F Flais, Department of Anaesthesiology, University Hospital of Caen R Leclercq, Department of Microbiology, University Hospital of Caen
Correspondence to: Dr D du Cheyron, Department of Medical Intensive Care, CHU de Caen, Av Cote de Nacre, 14000 Caen, France; ducheyron-d@chu-caen.fr

Accepted for publication 3 June 2003

\section{REFERENCES}

1 Campbell GD Jr, Silberman R. Drug-resistant Streptococcus pneumoniae. Clin Infect Dis 1998;26:1188-95.

2 Austrian R. Pneumococcal endocarditis, meningitis, and rupture of the aortic valve. Arch Intern Med 1957;99:539-44.

3 Gransden WR, Eykyn SJ, Phillips I. Pneumococcal bacteraemia: 325 episodes diagnosed at St Thomas's Hospital. BMJ (Clin Res Ed) 1985;290:505-8.

4 Aronin SI, Mukherjee SK, West JC, et al. Review of pneumococcal endocarditis in adults in the penicillin era. Clin Infect Dis 1998;26:165-71.

5 Auburtin M, Porcher R, Bruneel F, et al. Pneumococcal meningitis in the intensive care unit: prognostic factors of clinical outcome in a series of 80 cases. Am J Respir Crit Care Med 2002;165:713-17.

6 De Gans J, van de Beek D. Dexamethasone in adults with bacterial meningitis. N Engl J Med 2002;347:1549-56.

7 Karth G, Koreny M, Binder T, et al. Complicated infective endocarditis necessitating ICU admission: clinical course and prognosis. Crit Care 2002;6: 149-54.

8 Wolff $M$, Witchitz $S$, Chastang $C$, et al. Prosthetic valve endocarditis in the ICU. Prognostic factors of overall survival in a series of 122 cases and consequences for treatment decision. Chest 1995;108:688-94.

9 Lefort A, Mainardi JL, Selton-Suty C, et al. Streptococcus pneumoniae endocarditis in adults. A multicenter study in France in the era of penicillin resistance (1991-1998). The pneumococcal endocarditis study group. Medicine (Baltimore) 2000;79:327-37.

10 Siles Rubio JR, Anguita Sanchez M, Castillo Dominguez JC, et al. Austrian's syndrome (endocarditis, meningitis and pneumonia caused by Streptococcus pneumoniae). Apropos of a rare case. Rev Esp Cardiol 1998:51:1006-8.

11 Munoz P, Sainz J, Rodriguez-Creixems M, et al. Austrian syndrome caused by highly penicillin-resistant Streptococcus pneumoniae. Clin Infect Dis 1999;29:1591-2.

12 Begg N, Cartwright KA, Cohen J, et al. Consensus statement on diagnosis, investigation, treatment and prevention of acute bacterial meningitis in immunocompetent adults. British infection society working party. J Infect 1999;39:1-15

13 Martinez E, Miro JM, Almirante B, et al. Effect of penicillin resistance of Streptococcus pneumoniae on the presentation, prognosis, and treatment of pneumococcal endocarditis in adults. Clin Infect Dis 2002;35:130-9.

14 Annane D, Sebille V, Charpentier C, et al. Effect of treatment with low doses of hydrocortisone and fludrocortisone on mortality in patients with septic shock. JAMA 2002;288:862-71.

\section{$\mathrm{ECHO}$}

\section{$C D, A K$, and USpA share serum reactivity to yeast}

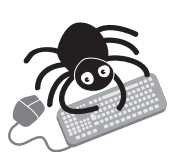

Please visit the Journal of Clinical Pathology website [www. jclinpath.com] for a link to the full text of this article.

\begin{abstract}
A n immunological study has provided more evidence that vertebral disease and coeliac disease $(C D)$ are related. For the first time patients with ankylosing spondylitis (AS) and undifferentiated spondyloarthropathy ( $\mathrm{USpA}$ ) have been shown to share a serum marker for CD.

The study compared serum IgA and IgG antibodies to Saccharomyces cerevisciae in patients with joint diseases and in patients with CD, with rheumatoid arthritis (RA) patients acting as controls for general inflammation, and with healthy controls. Serum IgA antibody was significantly raised in patients with AK and uSpA versus both controls, but not as high as in CD. These high antibody titres persisted over 12 weeks in a subgroup of 19 patients tested. Both IgG and IgA antibodies were significantly higher in CD than normal or RA controls. IgA antibody and bowel inflammation or intestinal lymphoid follicles were not related in AS or uSpA, but large prospective studies should tell whether high IgA leads eventually to CD, say the authors.

The study looked at 108 patients with joint disease: 43 with AS, 20 uSpA, and 45 PsA; 26 patients with CD; 56 patients with RA; and 45 healthy controls.

Evidence of a link between vertebral disease and CD has been mounting. Over two thirds of patients with joint disease have subclinical bowel inflammation and some develop CD. Their gut lining has more lymphoid follicles, regardless of its inflammatory state. Conversely, over a third of patients with $\mathrm{CD}$ has joint disease and meets criteria for SpA. So a common serum marker seemed likely.
\end{abstract}

$\Delta$ Annals of the Rheumatic Diseases 2003;62:455-459. 